\title{
Prediction of Mechanical Strength of Fiber Admixed Concrete Using Multiple Regression Analysis and Artificial Neural Network
}

\author{
S. Karthiyaini $\mathbb{D}^{1},{ }^{1}$ K. Senthamaraikannan ${ }^{D}{ }^{2}{ }^{2}$ J. Priyadarshini, ${ }^{3}$ Kamal Gupta, ${ }^{1}$ \\ and M. Shanmugasundaram (iD) \\ ${ }^{1}$ School of Mechanical and Building Sciences, Vellore Institute of Technology-Chennai Campus, Chennai-600127, Tamilnadu, \\ India \\ ${ }^{2}$ Department of Civil and Architectural Engineering, Al Musanna College of Technology, Muladdah Musanna, Oman \\ ${ }^{3}$ School of Computing Science and Engineering, Vellore Institute of Technology-Chennai Campus, Chennai-600127, Tamilnadu, \\ India
}

Correspondence should be addressed to M. Shanmugasundaram; shanmugaresearch@gmail.com

Received 28 September 2018; Accepted 21 March 2019; Published 7 May 2019

Guest Editor: Kazunori Fujikake

Copyright (c) 2019 S. Karthiyaini et al. This is an open access article distributed under the Creative Commons Attribution License, which permits unrestricted use, distribution, and reproduction in any medium, provided the original work is properly cited.

\begin{abstract}
The present study is to compare the multiple regression analysis (MRA) model and artificial neural network (ANN) model designed to predict the mechanical strength of fiber-reinforced concrete on 28 days. The model uses the data from early literatures; the data consist of tensile strength of fiber, percentage of fiber, water/cement ratio, cross-sectional area of test specimen, Young's modulus of fiber, and mechanical strength of control specimen, and these were used as the input parameters; the respective strength attained was used as the target parameter. The models are created and are used to predict compressive, split tensile, and flexural strength of fiber admixed concrete. These models are evaluated through the statistical test such as coefficient of determination $\left(R^{2}\right)$ and root mean squared error (RMSE). The results show that these parameters produce a valid model through both MRA and ANN, and this model gives more precise prediction for the fiber admixed concrete.
\end{abstract}

\section{Introduction}

Concrete is considered to be the fundamental and an important material in construction industry. Maintaining and testing the quality and behavior of concrete is the challenge faced by the industries in recent times. Also, the modeling of materials through regression tools and AI tools is recently increasing due to its accurate prediction and evaluation. The concrete as generally known for its good compressive behavior is made to behave well under tension and flexure through addition of fiber additives. The general tensile and flexural strength enhancements are made through addition of fibers made up of various materials with different physical and chemical properties. The addition of fibers made up of various materials changes the behavior of cement-based composites and enhances the toughness, tension resistance, and flexural resistance [1-9]. These fibers act at various levels in altering the mechanical behavior of concrete and thus defy the rules framed for its tensile and flexural performance, making it hard to predict. The major factors that act in enhancing the tensile and flexural strength are fiber distribution and its physical parameters. In recent years, analyzing the concrete properties through prediction modeling is gaining importance due to its accuracy and effectiveness in real-time application. These concrete models were presumed to predict the strength development through certain factors which are used as input parameters. This prediction facilitates in making decision on concrete mix and material selection [10-15]. But there is a challenge when creating a model of concrete for predicting tensile strength and flexural strength, as an effective prediction model is not created through parameters which were used for predicting the compressive strength [16-18]. The challenge on accuracy in prediction increases in fiber admixed concrete while predicting tensile strength and flexural strength; this is due to the fiber properties and its distribution.

In this study, the predictive model was created through multiple regression analysis (MRA) and artificial neural 
network (ANN). The fiber properties were used as parameters along with basic concrete and fiber parameters with single target system, and the model is tested through statistical tools for its performance.

\section{Prediction Modeling and Testing}

The model created here is for fiber-reinforced concrete; the data set was collected for steel fiber, polypropylene fiber, hybrid fiber, glass fiber, and basalt fiber from early studies. The actual compressive strength, split tensile strength, and flexural strength are taken as the target values based on the following parameters which are used as input parameters:

(1) Tensile strength of fiber (F)

(2) Percentage of fiber $(\mathrm{P})$

(3) Water/cement ratio (R)

(4) Cross-sectional area of test specimen (A)

(5) Young's modulus of fiber $(\mathrm{Y})$

(6) Mechanical strength of control specimen (S)

Based on the input parameter and target values, the output was generated through ANN and MRA, and these output values were compared with target (actual) values. The types of fibers and its respective literature source are presented in Table 1 . The active compressive strength data set has 5 columns and 252 rows $(5 \times 252)$ of input data and 1 column and 252 rows $(1 \times 252)$ of target data. The active split tensile strength data set has 5 columns and 119 rows $(5 \times 119)$ of input data and 1 column and 119 rows $(1 \times 119)$ of target data. The active flexural strength data set has 5 columns and 150 rows $(5 \times 150)$ of input data and 1 column and 150 rows $(1 \times 150)$ of target data. The target data for compressive strength, split tensile strength, and flexural strength were used in both the MRA and ANN model as separate target in this study. This single target system was used due to the usage of cross-sectional area of test specimens as one of the parameters, and it was known that the shape of the specimens varies with different mechanical strengths.

2.1. Prediction Model and Its Statistical Test. Two prediction models, artificial neural network (ANN) and multiple regression analysis (MRA), are used in this study to predict the compressive strength, split tensile strength, and flexural strength of fiber-reinforced concrete (FRC).

2.2. Artificial Neural Network (ANN). The ANN prediction model is programmed through MATLAB with two hidden layers, 15 neurons in each hidden layer and one output layer with dependent variable as compressive strength, split tensile strength, and flexural strength. Among all the data, approximately $70 \%, 15 \%$, and $15 \%$ has been considered for training, testing, and validation, respectively. The LevenbergMarquardt (LM) algorithm is used for training due to its robustness and speed. Layered feed-forward networks have been used in this algorithm, in which the neurons are arranged in layers. Here, signals are sent forward, and errors are propagated backwards.
2.3. Multiple Regression Analysis (MRA). In this study, the linear-type multiple regression analysis modeling is carried out using MS excel. The coefficients of regression are calculated by considering $95 \%$ confidence level; hence, the error tolerance level is limited to maximum of $5 \%$. For a given input variable, the calculated probability value ( $p$ value) is considered to be significant, if and only if its value is less than 0.05 . Through the regression analysis, the following coefficients presented in Table 2 were found and substituted in linear multiple regression equation (equation (1)):

output $=I+C_{1} F+C_{2} P+C_{3} R+C_{4} A+C_{5} Y+C_{6} S$.

2.4. Statistical Test. The performance of the ANN and MRA prediction for the mechanical behavior was tested through the statistical methods. The tests involved are coefficient of determination $\left(R^{2}\right)$ and root mean squared error (RMSE). The coefficient of determination is presented in equation (2). This can be obtained from the comparative chart of predicted compressive strength vs. experimental compressive strength. The accuracy of the predictions of a network was quantified by the root of the mean squared error difference (RMSE), between the experimented and the predicted values, and the procedure of finding RMSE is presented in equation (3):

$$
\begin{aligned}
R^{2} & =1-\frac{\text { sum of squares of residuals }}{\text { sum of sqaures of predicted values }}, \\
\text { RMSE } & =\sqrt{\frac{1}{n} \sum_{i=1}^{n}(A C S T-P C S T)^{2} .}
\end{aligned}
$$

\section{Results and Discussion}

The effectiveness and the acceptance of prediction models are based upon the ability of the model to predict the output. In this study, the models were designed to predict the mechanical behavior (mechanical strength) of FRC based on input parameters, and two methods of predictions, ANN and MRA, are used. The prediction models are validated through coefficient of determination $\left(R^{2}\right)$ and root mean squared error (RMSE) and are consolidated in Table 3.

The MRA and ANN prediction of the compressive strength value is plotted with respect to the actual compressive strength and presented in Figures 1 and 2, respectively. The MRA prediction has the coefficient of determination $R^{2}$ as 0.93 which is almost an acceptable value, whereas the ANN has an $R^{2}$ value of 1 which indicates that the ANN model is accurate. The RMSE of the MRA model is $7.23 \mathrm{MPa}$, and the ANN model is $0.14 \mathrm{MPa}$ which demonstrates that error in the MRA model is large and cannot be relied upon for predicting the compressive strength.

The MRA and ANN prediction model plot for split tensile strength with respect to its actual value is presented in Figures 3 and 4 , respectively. The $R^{2}$ value for the MRA model is 0.87 and ANN model is 0.94. The RMSE for the 


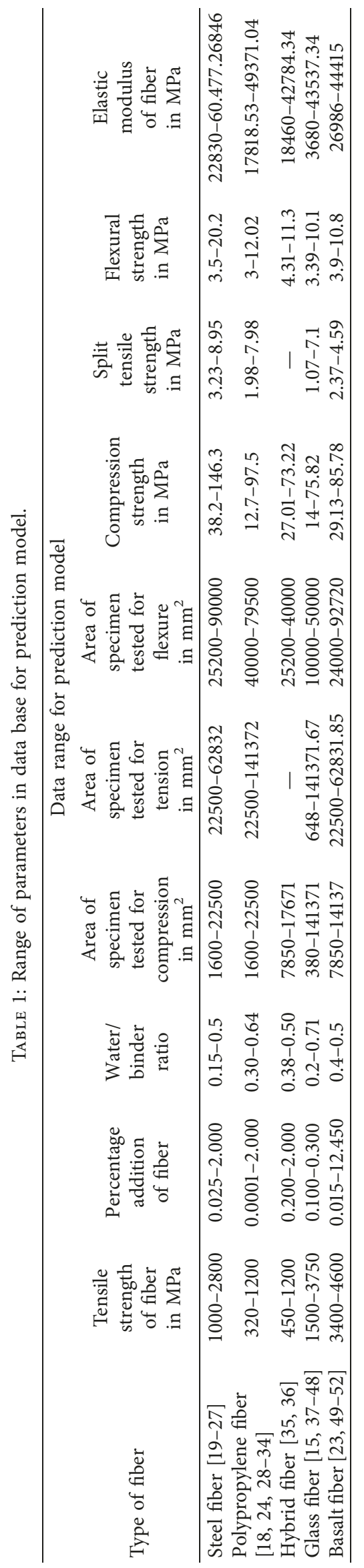


TABLE 2: Multiple regression analysis coefficients.

\begin{tabular}{lccc}
\hline $\begin{array}{l}\text { MRA } \\
\text { coefficients }\end{array}$ & $\begin{array}{c}\text { Coefficients for } \\
\text { compressive } \\
\text { strength }\end{array}$ & $\begin{array}{c}\text { Coefficients for } \\
\text { split tensile } \\
\text { strength }\end{array}$ & $\begin{array}{c}\text { Coefficients } \\
\text { for flexural } \\
\text { strength }\end{array}$ \\
\hline$I$ & -2.083944795 & 2.864487059 & 7.214539466 \\
$C_{1}$ & 0.000669227 & $5.24726 \times 10^{-05}$ & $-4.23499 \times 10^{-05}$ \\
$C_{2}$ & 1.097340646 & 0.81644571 & 0.513456489 \\
$C_{3}$ & -31.43416778 & -6.912788644 & -13.36882713 \\
$C_{4}$ & $-5.56151 \times 10^{-05}$ & $8.71841 \times 10^{-06}$ & $1.9284 \times 10^{-05}$ \\
$C_{5}$ & 0.001154844 & $4.70901 \times 10^{-05}$ & $2.60556 \times 10^{-05}$ \\
$C_{6}$ & 0.569536979 & 0.475257898 & 0.551752286 \\
\hline
\end{tabular}

TABLE 3: Statistical test conducted on prediction models.

\begin{tabular}{lcccc}
\hline \multirow{2}{*}{ Predicted parameters } & \multicolumn{2}{c}{ MRA } & \multicolumn{2}{c}{ ANN } \\
& $R^{2}$ & RMSE & $R^{2}$ & RMSE \\
\hline Compression strength & 0.93 & 7.23 & 1.00 & 0.14 \\
Split tensile strength & 0.87 & 0.70 & 0.94 & 0.42 \\
Flexural strength & 0.92 & 0.99 & 0.94 & 0.79 \\
\hline
\end{tabular}

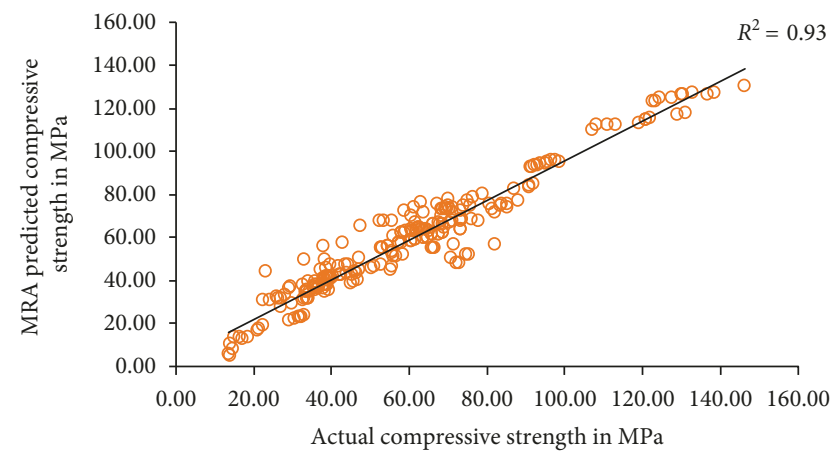

Figure 1: Actual vs. MRA predicted value for compressive strength.

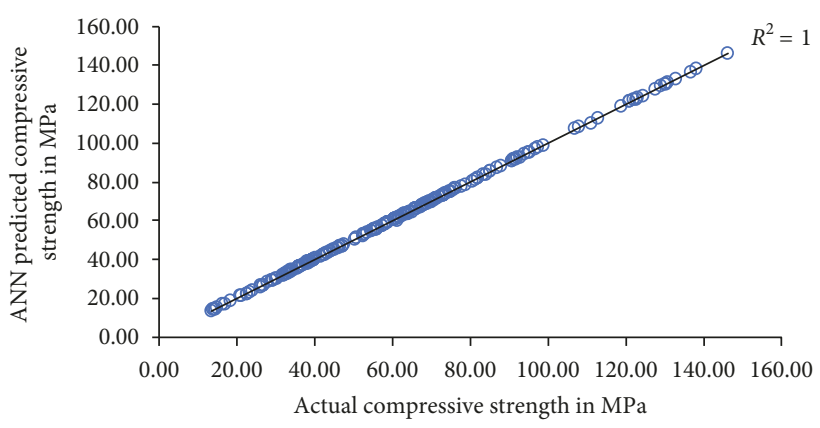

Figure 2: Actual vs. ANN predicted value for compressive strength.

MRA model is $0.70 \mathrm{MPa}$ and ANN is $0.42 \mathrm{MPA}$. The statistical validation of the split tensile strength model shows that both the MRA model and ANN model are in acceptable limit; even though ANN shows more accuracy than MRA, the mathematical model is also predicting the split tensile strength in par with the ANN model. From Figure 3, it is observed that the MRA model predicts to a high accuracy until actual split tensile strength is $4 \mathrm{MPa}$, after which the

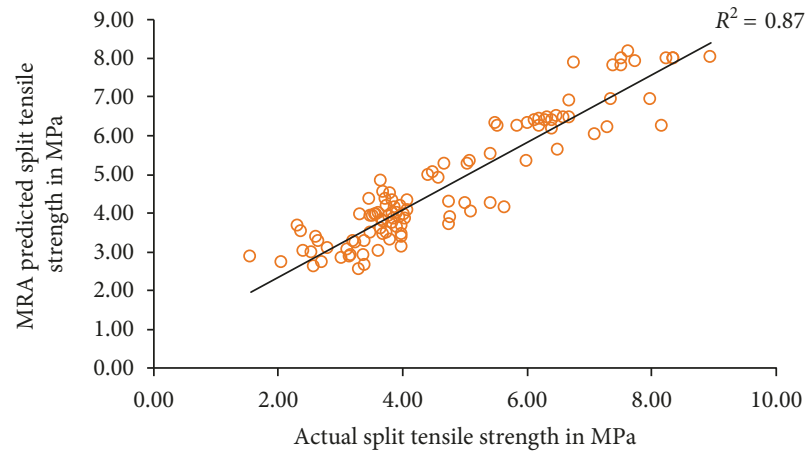

FIgURe 3: Actual vs. MRA predicted value for split tensile strength.

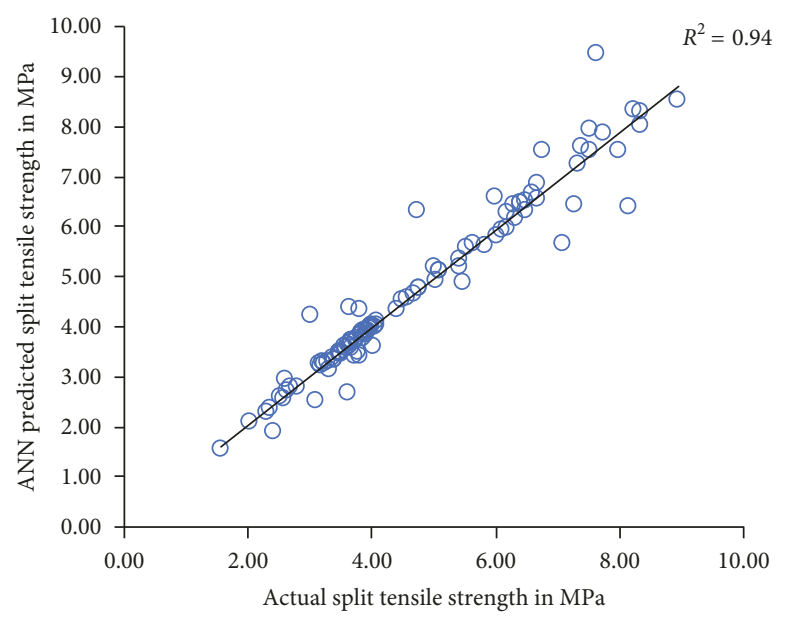

FIgURE 4: Actual vs. ANN predicted value for split tensile strength.

scatter plots were deviating from the actual trend line. From Figure 4, it is observed that the ANN prediction is accurate until the actual strength is $7.5 \mathrm{MPa}$, after which the scattered plot almost does not fit the trend line.

The MRA and ANN prediction model plot for flexural strength with respect to its actual value is presented in Figures 5 and 6 , respectively. The $R^{2}$ value for MRA and ANN was 0.92 and 0.94 , respectively, which has similar validation value. The RMSE value of the MRA model is $0.99 \mathrm{MPa}$ and ANN model is $0.79 \mathrm{MPa}$. Both the MRA and ANN were having similar model behavior in terms of statistical validation and graphical representation through Figures 5 and 6 . The prediction is accurate in both MRA and ANN models until the actual flexural strength is $9 \mathrm{MPa}$ after which the scattered plot is observed for both models. But there were fitted plots for the MRA model at higher actual flexural strength which lies between $13 \mathrm{MPa}$ and $14 \mathrm{MPa}$. This higher-order flexural strength fitness towards the trend line was not observed in the ANN model. The observation indicates that flexural strength prediction using MRA and ANN model has effectiveness, and more accurate prediction is rendered in both models. Through the three strength aspects, it was observed that the MRA gains its accurateness in predicting split tensile and flexural strength. The ANN predicts compressive strength to the maximum possible accuracy, and the prediction of split tensile strength and 


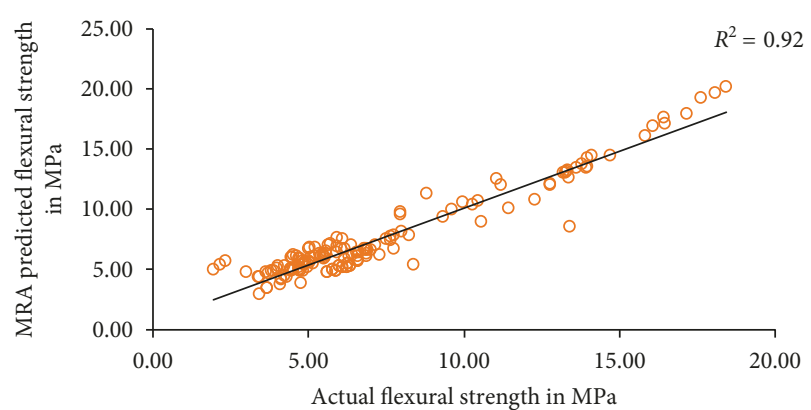

FIgURE 5: Actual vs. MRA predicted value for flexural strength.

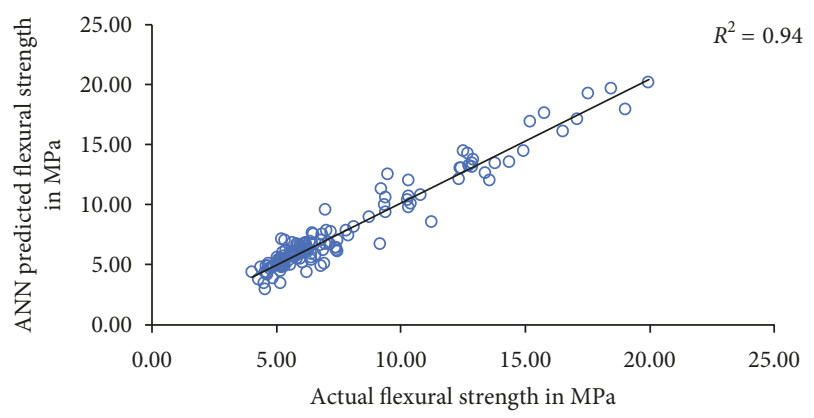

Figure 6: Actual vs. ANN predicted value for flexural strength.

flexural strength was also of higher accuracy. Though the fibers have various factors on influencing the strength development in concrete, the prediction models MRA and ANN are accurate by its output values. The ANN even though has its advantage of higher accuracy over MRA model; the performance of the MRA model is also efficient. The contribution of fiber properties in the prediction model proved to be effective and also gives more preciseness to the model. Earlier models that uses other parameters such as quantity of cement, admixtures, coarse aggregate, fine aggregate, and water were not able to perform well in prediction of tensile and flexural properties [53]; this limitation was overcome by the current model, where both the MRA and ANN model performs well with the given factors. Thus, both current models can predict the complete mechanical behavior of fiber admixed concrete with high precision.

\section{Conclusion}

This study investigated the feasibility of modeling a predictive analysis through earlier study data, converting the unstructured factors to possible structured parameters and using those in creating the MRA model and ANN model. Also, the effectiveness of these models is tested using statistical tools such as $R^{2}$ and RMSE. The compressive strength model shows that ANN has efficient prediction model with $R^{2}$ value in unity. The MRA model has $R^{2}$ value of 0.93 , but the error difference is $7.23 \mathrm{MPa}$ which is very high for a predictive model. The MRA model of split tensile strength and flexural strength shows high efficiency; even though the $R^{2}$ values are lesser than the compressive model, the performance of models is relatively strong. The ANN model for split tensile and flexural strength has similar statistical valuation. The MRA model shows more robustness while predicting the flexural strength, than the split tensile strength. Also, it is noted that the MRA model performs well in split tensile and flexural strength prediction and is validated through the $R^{2}$ and RMSE values. The MRA performs well similar to that of ANN and achieves half its effectiveness, except in compressive strength prediction. The study concludes that the fiber properties contribute high to the prediction model, thus increasing the models' performance.

\section{Data Availability}

The data supporting this work are available from previously reported studies and datasets, which have been cited. The processed data used to support the findings of this study are available from the corresponding author upon request.

\section{Conflicts of Interest}

The authors declare no conflicts of interest.

\section{References}

[1] X. Lu and C.-T. T. Hsu, "Behavior of high strength concrete with and without steel fiber reinforcement in triaxial compression," Cement and Concrete Research, vol. 36, no. 9, pp. 1679-1685, 2006.

[2] V. F. P. Dutra, S. Maghous, and A. C. Filho, "A homogenization approach to macroscopic strength criterion of steel fiber reinforced concrete," Cement and Concrete Research, vol. 44, pp. 34-45, 2013.

[3] P. S. Song and S. Hwang, "Mechanical properties of highstrength steel fiber-reinforced concrete," Construction and Building Materials, vol. 18, no. 9, pp. 669-673, 2004.

[4] M. L. Allan and L. E. Kukacka, "Strength and durability of polypropylene fibre reinforced grouts," Cement and Concrete Research, vol. 25, no. 3, 1995.

[5] B. Chen and J. Liu, "Residual strength of hybrid-fiberreinforced high-strength concrete after exposure to high temperatures," Cement and Concrete Research, vol. 34, no. 6, pp. 1065-1069, 2004.

[6] C. S. Poon, Z. H. Shui, and L. Lam, "Compressive behavior of fiber reinforced high-performance concrete subjected to elevated temperatures," Cement and Concrete Research, vol. 34, no. 12, pp. 2215-2222, 2004.

[7] Y. Ding, C. Azevedo, J. B. Aguiar, and S. Jalali, "Study on residual behaviour and flexural toughness of fibre cocktail reinforced self compacting high performance concrete after exposure to high temperature," Construction and Building Materials, vol. 26, no. 1, 2011.

[8] A. Avci, H. Arikan, and A. Akdemir, "Fracture behavior of glass fiber reinforced polymer composite," Cement and Concrete Research, vol. 34, no. 3, pp. 429-434, 2004.

[9] I. Curosu, V. Mechtcherine, and O. Millon, "Effect of fiber properties and matrix composition on the tensile behavior of strain-hardening cement-based composites (SHCCs) subject to impact loading," Cement and Concrete Research, vol. 82, pp. 23-35, 2016.

[10] İ. B. Topçu and M. Sarıdemir, "Prediction of compressive strength of concrete containing fly ash using artificial neural networks and fuzzy logic," Computational Materials Science, vol. 41, no. 3, pp. 305-311, 2008. 
[11] N. Al-Mutairi, M. Terro, and A.-L. Al-Khaleefi, "Effect of recycling hospital ash on the compressive properties of concrete: statistical assessment and predicting model," Building and Environment, vol. 39, no. 5, pp. 557-566, 2004.

[12] M. A. Kewalramani and R. Gupta, "Concrete compressive strength prediction using ultrasonic pulse velocity through artificial neural networks," Automation in Construction, vol. 15, no. 3, pp. 374-379, 2006.

[13] R. Siddique, P. Aggarwal, and Y. Aggarwal, "Prediction of compressive strength of self-compacting concrete containing bottom ash using artificial neural networks," Advances in Engineering Software, vol. 42, no. 10, pp. 780-786, 2011.

[14] Z. H. Duan, S. C. Kou, and C. S. Poon, "Prediction of compressive strength of recycled aggregate concrete using artificial neural networks," Construction and Building Materials, vol. 40, pp. 1200-1206, 2013.

[15] H. I. Erdal, O. Karakurt, and E. Namli, "High performance concrete compressive strength forecasting using ensemble models based on discrete wavelet transform," Engineering Applications of Artificial Intelligence, vol. 26, no. 4, pp. 1246-1254, 2013.

[16] A. Nazari and S. Riahi, "Computer-aided prediction of the $\mathrm{ZrO}_{2}$ nanoparticles' effects on tensile strength and percentage of water absorption of concrete specimens," Journal of Materials Science \& Technology, vol. 28, no. 1, pp. 83-96, 2012.

[17] M. Baena, A. Turon, L. Torres, and C. Miàs, "Experimental study and code predictions of fibre reinforced polymer reinforced concrete (FRP RC) tensile members," Composite Structures, vol. 93, no. 10, pp. 2511-2520, 2011.

[18] H. Fathi, T. Lameie, M. Maleki, and R. Yazdani, "Simultaneous effects of fiber and glass on the mechanical properties of self-compacting concrete," Construction and Building Materials, vol. 133, pp. 443-449, 2017.

[19] S. Yehia, A. Douba, O. Abdullahi, and S. Farrag, "Mechanical and durability evaluation of fiber-reinforced self-compacting concrete," Construction and Building Materials, vol. 121, pp. 120-133, 2016.

[20] M. Mastali and A. Dalvand, "Fresh and hardened properties of self-compacting concrete reinforced with hybrid recycled steel-polypropylene fiber," Journal of Materials in Civil Engineering, vol. 29, no. 6, article 04017012, 2017.

[21] W.-C. Liao, W. Perceka, and E.-J. Liu, "Compressive stressstrain relationship of high strength steel fiber reinforced concrete," Journal of Advanced Concrete Technology, vol. 13, no. 8, pp. 379-392, 2015.

[22] C. D. Atis, O. Karahan, K. Ari, Ö. C. Sola, C. Bilim, and F. Ash, "Relation between strength properties (flexural and compressive) and abrasion resistance of fiber (steel and polypropylene) reinforced fly ash concrete," Journal of Materials in Civil Engineering, vol. 21, no. 8, pp. 402-408, 2009.

[23] M. Z. N. Khan, Y. Hao, H. Hao, and F. U. A. Shaikh, "Mechanical properties of ambient cured high strength hybrid steel and synthetic fibers reinforced geopolymer composites," Cement and Concrete Composites, vol. 85, pp. 133-152, 2018.

[24] J. J. Li, C. J. Wan, J. G. Niu, L. F. Wu, and Y. C. Wu, "Investigation on flexural toughness evaluation method of steel fiber reinforced lightweight aggregate concrete," Construction and Building Materials, vol. 131, pp. 449-458, 2017.

[25] A. Caggiano, S. Gambarelli, E. Martinelli, N. Nisticò, and M. Pepe, "Experimental characterization of the post-cracking response in hybrid steel/polypropylene fiber-reinforced concrete," Construction and Building Materials, vol. 125, pp. 1035-1043, 2016.
[26] M. Hsie, C. Tu, and P. S. Song, "Mechanical properties of polypropylene hybrid fiber-reinforced concrete," Materials Science and Engineering: A, vol. 494, no. 1-2, pp. 153-157, 2008.

[27] L. Shan and L. Zhang, "Experimental study on mechanical properties of steel and polypropylene fiber-reinforced concrete," Applied Mechanics and Materials, vol. 584-586, pp. 1355-1361, 2014.

[28] H. Mohammadhosseini, A. S. M. Abdul Awal, and J. B. Mohd Yatim, "The impact resistance and mechanical properties of concrete reinforced with waste polypropylene carpet fibres," Construction and Building Materials, vol. 143, pp. 147-157, 2017.

[29] M. G. Alberti, A. Enfedaque, and J. C. Gálvez, "Fibre reinforced concrete with a combination of polyolefin and steelhooked fibres," Composite Structures, vol. 171, pp. 317-325, 2017.

[30] S. Fallah and M. Nematzadeh, "Mechanical properties and durability of high-strength concrete containing macropolymeric and polypropylene fibers with nano-silica and silica fume," Construction and Building Materials, vol. 132, pp. 170-187, 2017.

[31] M. Hassani Niaki, A. Fereidoon, and M. Ghorbanzadeh Ahangari, "Experimental study on the mechanical and thermal properties of basalt fiber and nanoclay reinforced polymer concrete," Composite Structures, vol. 191, pp. 231$238,2018$.

[32] A. M. Alhozaimy, P. Soroushian, and F. Mirza, "Mechanical properties of polypropylene fiber reinforced concrete and the effects of pozzolanic materials," Cement and Concrete Composites, vol. 18, no. 2, pp. 85-92, 1996.

[33] V. Afroughsabet and T. Ozbakkaloglu, "Mechanical and durability properties of high-strength concrete containing steel and polypropylene fibers," Construction and Building Materials, vol. 94, pp. 73-82, 2015.

[34] S. Iqbal, A. Ali, K. Holschemacher, and T. A. Bier, "Mechanical properties of steel fiber reinforced high strength lightweight self-compacting concrete (SHLSCC)," Construction and Building Materials, vol. 98, pp. 325-333, 2015.

[35] G. M. Ren, H. Wu, Q. Fang, and J. Z. Liu, "Effects of steel fiber content and type on static mechanical properties of UHPCC," Construction and Building Materials, vol. 163, pp. 826-839, 2018.

[36] P. Iyer, S. Y. Kenno, and S. Das, "Mechanical properties of fiber-reinforced concrete made with basalt filament fibers," Journal of Materials in Civil Engineering, vol. 27, no. 11, article 04015015, 2015.

[37] V. R. Sivakumar, O. R. Kavitha, G. Prince Arulraj, and V. G. Srisanthi, “An experimental study on combined effects of glass fiber and Metakaolin on the rheological, mechanical, and durability properties of self-compacting concrete," Applied Clay Science, vol. 147, pp. 123-127, 2017.

[38] S. Ahmad, A. Umar, and A. Masood, "Properties of normal concrete, self-compacting concrete and glass fibre-reinforced self-compacting concrete: an experimental study," Procedia Engineering, vol. 173, pp. 807-813, 2017.

[39] S. T. Tassew and A. S. Lubell, "Mechanical properties of glass fiber reinforced ceramic concrete," Construction and Building Materials, vol. 51, pp. 215-224, 2014.

[40] A. B. Kizilkanat, N. Kabay, V. Akyüncü, S. Chowdhury, and A. H. Akça, "Mechanical properties and fracture behavior of basalt and glass fiber reinforced concrete: an experimental study," Construction and Building Materials, vol. 100, pp. 218-224, 2015. 
[41] M. Khan and M. Ali, "Use of glass and nylon fibers in concrete for controlling early age micro cracking in bridge decks," Construction and Building Materials, vol. 125, pp. 800-808, 2016.

[42] A. Hanif, P. Parthasarathy, Z. Lu, M. Sun, and Z. Li, "Fiberreinforced cementitious composites incorporating glass cenospheres - mechanical properties and microstructure," Construction and Building Materials, vol. 154, pp. 529-538, 2017.

[43] M. E. Arslan, "Effects of basalt and glass chopped fibers addition on fracture energy and mechanical properties of ordinary concrete: CMOD measurement," Construction and Building Materials, vol. 114, pp. 383-391, 2016.

[44] T. A. Söylev and T. Özturan, "Durability, physical and mechanical properties of fiber-reinforced concretes at lowvolume fraction," Construction and Building Materials, vol. 73, pp. 67-75, 2014.

[45] R. M. Novais, J. Carvalheiras, M. P. Seabra, R. C. Pullar, and J. A. Labrincha, "Effective mechanical reinforcement of inorganic polymers using glass fibre waste," Journal of Cleaner Production, vol. 166, pp. 343-349, 2017.

[46] T. Simões, H. Costa, D. Dias-da-Costa, and E. Júlio, "Influence of fibres on the mechanical behaviour of fibre reinforced concrete matrixes," Construction and Building Materials, vol. 137, pp. 548-556, 2017.

[47] G. B. Maranan, A. C. Manalo, B. Benmokrane, W. Karunasena, and P. Mendis, "Evaluation of the flexural strength and serviceability of geopolymer concrete beams reinforced with glass-fibre-reinforced polymer (GFRP) bars," Engineering Structures, vol. 101, pp. 529-541, 2015.

[48] W. H. Kwan, M. Ramli, and C. B. Cheah, "Flexural strength and impact resistance study of fibre reinforced concrete in simulated aggressive environment," Construction and Building Materials, vol. 63, pp. 62-71, 2014.

[49] J. Branston, S. Das, S. Y. Kenno, and C. Taylor, "Mechanical behaviour of basalt fibre reinforced concrete," Construction and Building Materials, vol. 124, pp. 878-886, 2016.

[50] U. Larisa, L. Solbon, and B. Sergei, "Fiber-reinforced concrete with mineral fibers and nanosilica," Procedia Engineering, vol. 195, pp. 147-154, 2017.

[51] T. Ayub, N. Shafiq, and S. U. Khan, "Compressive stress-strain behavior of HSFRC reinforced with basalt fibers," Journal of Materials in Civil Engineering, vol. 28, article 06015014, 2016.

[52] M. Abdulhadi and Liaoning University of Technology, Jinzhou, "A comparative study of basalt and polypropylene fibers reinforced concrete on compressive and tensile behavior," International Journal of Engineering Trends and Technology, vol. 9, no. 6, pp. 295-300, 2014.

[53] M. F. M. Zain, H. B. Mahmud, A. Ilham, and M. Faizal, "Prediction of splitting tensile strength of high-performance concrete," Cement and Concrete Research, vol. 32, no. 8, pp. 1251-1258, 2002. 


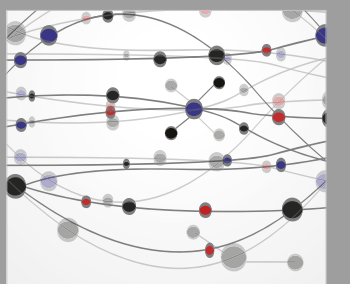

The Scientific World Journal
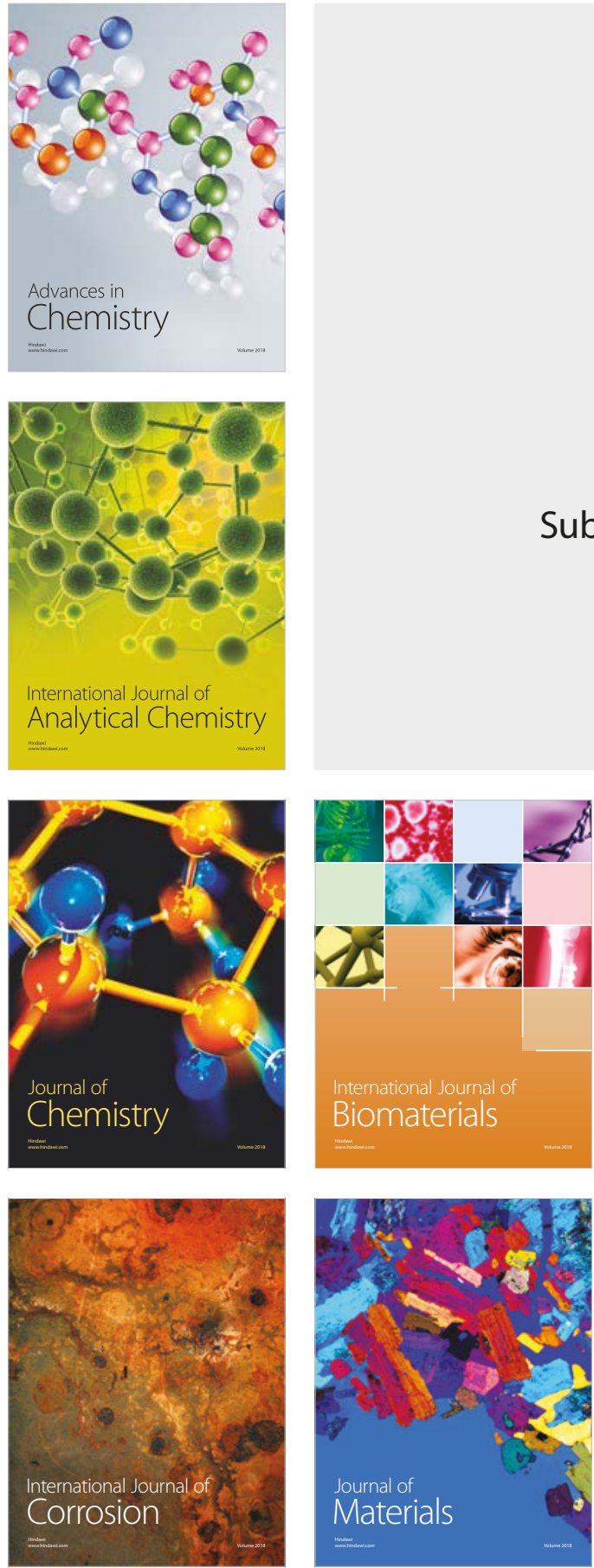

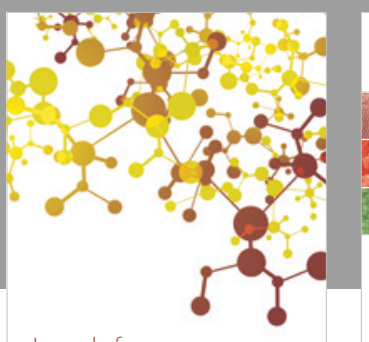

Journal of

Applied Chemistry
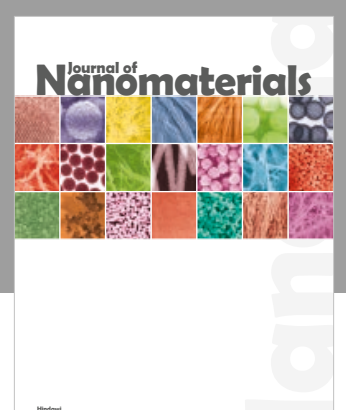

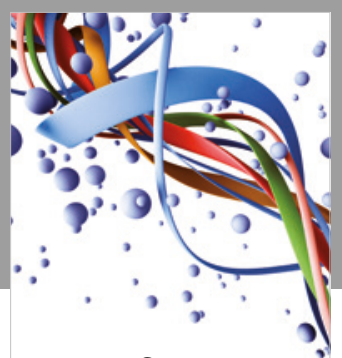

Scientifica

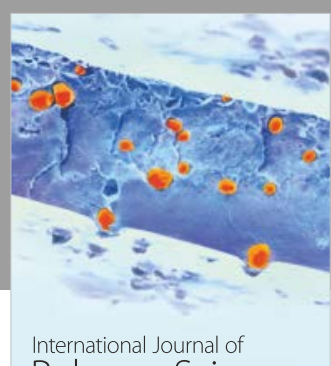

Polymer Science

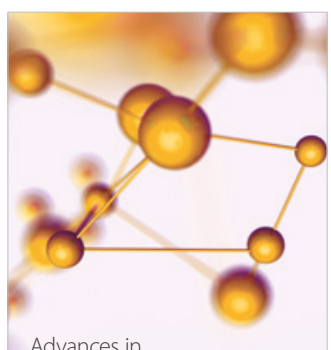

Physical Chemistry
